\title{
Chapter 1 \\ Indigenous Pathways and Transitions into Higher Education: An Introduction
}

\author{
Jack Frawley, Steve Larkin, and James A. Smith
}

\section{Introduction}

University is not for everyone, but a university should be for everyone. To a certain extent, the choice not to participate in higher education should be respected given that there are other avenues and reasons to participate in education and employment that are culturally, socially and/or economically important for society. Those who choose to pursue higher education should do so knowing that there are multiple pathways into higher education and, once there, appropriate support is provided for a successful transition.

In 2005 the Indigenous Higher Education Advisory Council (IHEAC) established seven priority areas to increase the participation of Indigenous people in universities. One of the priorities included encouraging universities to work with schools, Technical and Further Education (TAFE) colleges, Vocational Education and Training (VET) providers and other registered training organisations to build pathways into higher education for Indigenous students (Bexley et al. 2008). Examples of pathways include school outreach programs ${ }^{1}$, special admission schemes and bridging programs.

\footnotetext{
${ }^{1}$ Spelling adheres to Standard Australian English.

J. Frawley $(\bowtie)$

National Centre for Cultural Competence, University of Sydney, Sydney, NSW, Australia

e-mail: jack.frawley@ sydney.edu.au

S. Larkin

Pro Vice-Chancellor Indigenous Education and Research, University of Newcastle,

Newcastle, NSW, Australia

e-mail: steven.larkin@newcastle.edu.au

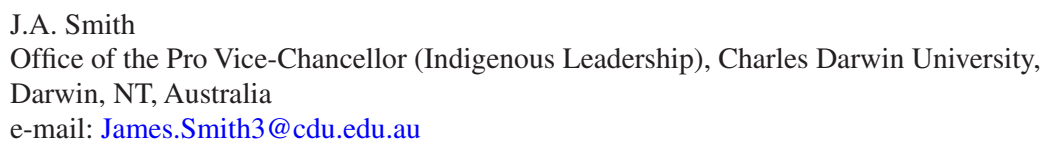


Pathways are viewed as a mechanism to redress disadvantage because of the second chance they provide. Nevertheless, they can be daunting, involving a combination of personal, institutional and systemic challenges. Also, pathways and transitions for Indigenous ${ }^{2}$ students into higher education can be complex because of the social, cultural, economic and educational challenges they present resulting in concerns relating to equity and social inclusion. The challenge for universities is to create socially just pathways. This challenge could also extend to the question of what counts as 'knowledge'; that is, what 'second-chance' students bring to the academy and how this is recognised. Inherent in using pathways is the issue of student transition. Drawing on the results of several Office of Learning and Teaching (OLT) projects, Gale and Parker (2011, p. 25) define transition as the capacity to navigate change which includes having 'the resources to engage with change, without having full control over and/or knowledge about what the change involves'. Research by Jackson (2003, p. 341) shows that the transition to university 'represents a period of disequilibrium as students move from a familiar environment into an unfamiliar one', resulting in 'significant life changes' and discontinuity, which can pose threats to self-identity. Gale and Parker (2011, p. 36) conclude that the issue of 'student transitions into HE should be cognisant of students' lived reality, not just institutional and/or systemic interest'.

\section{Relevant Policies and Reviews}

Social inclusion and equity in higher education issues have been addressed by consecutive Australian government policies and reviews. It is not intended to name them all here but, rather, to draw attention to the policies and reviews that focus on social inclusion and equity with an emphasis on pathways and transitions, particularly in Indigenous contexts (Kinnane et al. 2014). These policies and reviews include the Report of the House of Representatives Select Committee on Aboriginal Education (1985). This report shifted the policy from welfare towards equity which resulted in an increase in higher education enrolments by Indigenous students. The Aboriginal Participation Initiative (1985) allocated additional funding for Indigenous students to attend higher education, whilst 2 years later, the Aboriginal Employment Development Policy (1987) emphasised equitable participation in tertiary education. In 1988, the Report of the Aboriginal Education Policy Task Force presented objectives and strategies for schooling and tertiary education; and the Commonwealth Government's Higher Education: A policy statement made a commitment to Indigenous higher education participation and graduation targets, and the development of a National Aboriginal Education Policy (NAEP). The NAEP, which later became the National Aboriginal and Torres Strait Islander Education Policy (NATSIEP), came into effect on January 1, 1990. The policy identified 21

\footnotetext{
${ }^{2}$ The term 'Indigenous', in the Australian context, is used in this book to refer to Australian Aboriginal and Torres Strait Islander people.
} 
long-term goals focusing on Indigenous involvement in educational decisionmaking, equality of access to education services, equity of educational participation, and equitable and appropriate educational outcomes. Five of these goals specifically addressed higher education aspirations. All 21 long-term goals were later aggregated into 8 priorities for action.

The higher education policy statement, A Fair Chance for All (1990), aimed to ensure that all groups in society had the opportunity to participate in higher education and identified six target groups for widening participation. These equity groups were Indigenous Australians; people from a non-English-speaking background who had arrived in Australia within the last 10 years; people with disabilities; people from rural and isolated areas; women, particularly those engaged in non-traditional areas of study; and people from socio-economically disadvantaged backgrounds (Department of Employment, Education and Training 1990). In 2001, the Ministerial Council on Education, Employment, Training and Youth Affairs (MCEETYA) Taskforce On Indigenous Education released a discussion paper, Exploring Multiple Pathways for Indigenous Students, which in part summarised Indigenous participation and attrition rates in higher education and reported on a range of academic and institutional factors that impacted on the experience of educational success for Indigenous Australians. IHEAC issued its first report in 2006 which, among other things, presented priority areas for pathways into higher education and the need for increases in Indigenous student enrolment, retention, and research.

In 2008 the Australian Government commissioned a review of the nation's higher education sector: the Bradley Review (Bradley et al. 2008). The Bradley Review noted the successes in regard to gender inequity in higher education, regional and remote area students, Indigenous students and those from low socio-economic status (SES) backgrounds were still seriously under-represented. It also found that the major barriers to the participation of students from low SES backgrounds were educational attainment, lower awareness of the long-term benefits of higher education, lower aspiration to participate and the potential need for extra financial, academic or personal support once enrolled in higher education courses. In 2009 the Australian Government's policy, Transforming Australia's Higher Education System, announced two targets for the higher education sector: that by 2020,20\% of undergraduate university students should be from low socio-economic backgrounds; and that by $2025,40 \%$ of 25 - to 34-year-olds should hold a bachelor's degree. To support this policy, the Higher Education Participation and Partnerships Program (HEPPP) initiative was established. The participation component offers universities financial incentives to enrol and retain students from low SES backgrounds; the partnerships component provides funding to raise students' aspirations for higher education, and to this end works in partnership with other education institutions (Gale and Parker 2013).

The most recent review into Indigenous higher education, the Behrendt Review (Behrendt et al. 2012), called for initiatives to unlock the capacity, and empower the choices, of Indigenous students by building the necessary skills and knowledge to 'help individuals reach a point where they are eligible to enter higher education, should they so choose; and to inform their aspirations regarding higher education, 
particularly in relation to beliefs about who "belongs" at university and who doesn't' (Naylor et al. 2013, p. 14). Behrendt et al. (2012) also drew attention to the dysfunctional education pipeline which impacts on pathways. Consequently, there have been subsequent competitive grant rounds investing in Indigenous-focused HEPPP projects in response to the recommendations arising from the Behrendt Review.

The above policy trajectory has shaped the way in which higher education has been shaped to support Indigenous access and participation in higher education (Liddle 2016). However, to ensure that improved Indigenous higher education outcomes are achieved, we need to have a better understanding of what the pathways and transitions into, and out of, higher education look like and how they are best supported.

\section{Indigenous Pathways and Transitions Themes}

In October 2015, the Office of the Pro Vice-Chancellor Indigenous Leadership at Charles Darwin University hosted a National Forum on Indigenous pathways and transitions into higher education within the Australian Centre for Indigenous Knowledges and Education precinct in Darwin. This was funded by the Australian Government through the Higher Education Participation and Partnerships Program (HEPPP). The theme of the Forum was Engagement at the interface: Indigenous pathways and transitions into Higher Education. The intended outcomes of the Forum were to

(a) Facilitate networking, share information and create a national dialogue about Indigenous pathways and transitions into higher education

(b) Provide a culturally safe opportunity to share stories and emerging evidence about Indigenous pathways and transitions into higher education

(c) Generate and document an evidence-base about the most effective approaches for supporting Indigenous pathways and transitions into higher education

(d) Explore different and innovative approaches and strategies that incorporate Indigenous knowledges and practices into the development and implementation of Indigenous-focused pathways and transitions into higher education

(e) Generate and document an evidence-base about the most effective approaches for supporting Indigenous pathways and transitions into higher education

The Forum was divided into substantive sessions, working groups, poster presentations, workshops and yarning circles which provided delegates the opportunity to focus on specific areas from their own HEPPP perspectives and experiences. Whilst some presentations were published as papers in a special issue of the Learning Communities: International Journal of Learning in Social Contexts, others were developed into chapters for this book. Indeed, this book draws on the most pertinent discussions and presentations from the Forum and explicitly addresses Indigenous pathways, transition and participation in higher education. The majority of chapters relate to Australia, although we, as co-editors, made a conscious decision to include 
some international contributions from both Canada and the USA. Issues raised by the authors are collated around four broad themes: policy and systems; engagement; pathways; and transitions, participation and success.

\section{Policy and Systems}

Systems thinking has the potential to 'shift the focus of the action towards considerations of the purpose of higher education and how to better achieve the preferred ends' (Houston 2008, p. 145). Systems thinking considers the issues of linking planning, quality improvement and institutional research. A systems approach develops holistic understanding and promotes 'a process of intervention that is responsive to the emerging understanding of a complex situation' (Houston 2008, p. 149). Systems thinking is evident at the policy level, whether government or institutional, and can be applied in a variety of ways through targeted initiatives and strategies. At a government level, the parallel policy focus on the broad national equity agenda, and the more specific Indigenous higher education agenda, can be both complementary and divergent. These contrasting positions are particularly evident in the implementation of respective equity and Indigenous programs in higher education institutions across Australia. The unique theoretical dimensions and principles underpinning higher education policy agendas can create both synergies and tensions.

At an institutional level, applied policy is evident through established initiatives and strategies. Some Australian universities have adopted a whole-of-university approach to improving Indigenous education and employment by incorporating several university approaches and actions into one coherent direction that brings together key areas of student services, employment and governance, teaching and learning, research, human resources, community engagement and international outreach. The whole-of-university approach includes embedding cultural competence. Universities Australia (2011, p. 3) defines cultural competence as:

Student and staff knowledge and understanding of Indigenous Australian cultures, histories and contemporary realities and awareness of Indigenous protocols, combined with the proficiency to engage and work effectively in Indigenous contexts congruent to the expectations of Indigenous Australian peoples.

A whole-of-university approach to cultural competence would ensure Indigenous involvement in university governance, management, teaching and learning, and research and a greater presence of Indigenous staff in the academy. It would also mean that universities establish stronger and more meaningful partnerships with Indigenous communities, especially those within their geographical regions. Such an approach means that systems thinking is realised and driven from the bottom-up. 


\section{Engagement}

Engagement that supports participation in higher education is characterised by a number of dimensions: 'engagement through teaching and learning, curriculum design, policies, research, external relations, social and cultural engagement, partnerships with school and educational providers, economic engagement, and organisation and participation of students' (Bernardo et al. 2012, pp. 188-189). More recent scholarship has also advocated for whole of community engagement approaches that involve family engagement approaches and engagement with sectors and services that traditionally may sit outside of the education realm, including Aboriginal community-controlled organisations and local government. In practice this means that engaged universities create a more accessible, outward reaching and inclusive society where universities and communities work together to monitor partnerships, measure impacts, evaluate outcomes, and make improvements to their shared activities.

Engagement requires partnerships. Equitable partnership approaches involve individuals, community members, organisational representatives, and researchers in all aspects of community engagement. Partners contribute their expertise and share responsibilities and ownership to increase understanding and incorporate the knowledge gained with the engagement. Partnership approaches build on strengths and resources within the community; facilitate collaborative, equitable involvement of all partners; integrate knowledge and action for the mutual benefit of all partners; and disseminate program findings and knowledge gained to all (Israel et al. 2001).

\section{Pathways}

The concept of pathways addresses concerns around equity and social inclusion. Pathways into university can be difficult for students and their families to navigate. They are rarely linear. There can be multiple entry and exit points, and there can be many enablers and barriers that impact upon what pathways look like and how they are experienced. The centrality of pathways can depend on the sense of community within a university; access to adequate support structures; and the provision of a safe study environment in which students feel confident to learn and grow. Pathways are viewed as a mechanism to redress disadvantage because of the second chance they provide. However, Wheelahan (2009, p. 262) warns that this 'reinforces the notion that students need a second-chance because of their presumed deficits, rather than the institutional practices of universities and the extent to which they are prepared to accept such students'. The challenge for Universities is to create socially just pathways that are pertinent to the needs of Indigenous learners.

In its submission to the Bradley Review (Bradley et al. 2008), IHEAC stated that Indigenous students who enter the academy do so with significant strengths in 
knowledge and experiences and that this should be recognised. Parent (2014, p. 59) states that Indigenous Knowledges (IK).

encompass the technological, social, economic, philosophical, spiritual, educational, legal and governmental elements of particular Indigenous cultures throughout the world. As Indigenous Knowledges are context-specific and interwoven within a given community's lived experience, they are dynamic and ever-changing to reflect environmental and social adaptations. Indigenous Knowledges are therefore not a singular body of knowledge but are multi-dimensional and pluralistic in that they contain many layers of being, knowing, and modes of expression.

The argument for the inclusion of Indigenous Knowledge (IK) in higher education goes beyond Indigenous perspectives across the curriculum to one in which the 'discipline areas may themselves be challenged' (Bradley et al. 2008, p. 33). IK is now considered in many universities to be essential to the academy and is referenced in individual university's Indigenous Education Statements, Reconciliation Action Plans and/or strategic plans or frameworks, and many universities report on how IK is put into practice through teaching and learning initiatives. Nevertheless, IK within the academy calls for transformative practice, not just within teaching and learning, but what it means for the student experience (Martin 2016).

\section{Transition, Participation, and Success}

Transitions into the academy require developing the students' capacity to change and providing support to enable that change (Liddle 2016). Students will require a sense of purpose of being in the academy, and this will include a clear understanding of content and pedagogy and engagement with their peers and with university life (Naylor et al. 2013). For Indigenous students to be fully supported, Nakata (2012) believes that it must go beyond the pedagogy of the academy to include interventions that will manage students at risk, monitor and track students, and provide timely assistance in the decoding the knowledge of the disciplines. Transitions need to include pedagogy. Nakata (2012, p. A-3) warns that too often 'assistance comes after the fact of failure, at the point of full-blown crisis, when it is all but too late'. Liddle (2016) has also emphasised that the deficit approaches of the current system hinder Indigenous participation in higher education and that capacitybuilding approaches now need to take centre stage.

In a recent report (Kinnane et al. 2014, p.10) it was stated that 'success exists on a spectrum defined by individual and collective terms, as well as a range of measures utilised by universities and government departments'. Success was viewed not so much as measured outcomes but more as a 'ripple effect of many small successes'. Also, the report identified that successful transition into higher education through targeted pathway programs critically depended upon supportive family and community relationships, dispelled myths and raised expectations. 


\section{Conclusion}

Some argue that pathways, transition and participation issues go beyond improving the student learning experience to the "need for a curriculum that provides room for different ways of thinking about, and different ways of engaging with knowledge, and inserting different kinds of understandings into the learning environment and experience that perhaps have not been part of Australian HE before' (Gale 2012, pp. 252-253). For Nakata et al. (2008, p. 142) this shifts the responsibility solely of the student to a shared experience where academics come to understand the Indigenous students struggle with course content in 'ways that are meaningful and purposeful for their future professional goals and collective Indigenous ends' and to a teaching position 'that provides better opportunities for negotiation between Indigenous and non-Indigenous meanings'. These are the challenges for higher education to ensure that each university is a place for everyone.

\section{References}

Behrendt, L., Larkin, S., Griew, R., \& Kelly, P. (2012). Review of higher education access and outcomes for aboriginal and Torres Strait islander people: Final report. Canberra: Department of Industry, Innovation, Science, Research and Tertiary Education.

Bernardo, M. A. C., Butcher, J., \& Howard, P. (2012). An international comparison of community engagement in higher education. International Journal of Educational Development, 32(1), 187-192.

Bexley, E., Anderson, A., Devlin, M., Garnett, R., Marginson, S., \& Maxwell, L. (2008). Participation and equity: A review of the participation in higher education of people from low socioeconomic backgrounds and indigenous people. Melbourne: Centre for the Study of Higher Education.

Bradley, D., Noonan, P., Nugent, H., \& Scales, B. (2008). Review of Australian higher education: Final report. Canberra: Department of Education, Employment and Workplace Relations.

Department of Employment Education and Training. (1990). A fair chance for all: Higher education that'swithin everyone's reach. Canberra: AGPS.

Gale, T. (2012). Towards a southern theory of student equity in Australian higher education: Enlarging the rationale for expansion. International Journal of Sociology of Education, 1(3), 238-262.

Gale, T., \& Parker, S. (2011). Good practice report: Student transition into higher education. Surry Hills: Australian Learning and Teaching Council.

Gale, T., \& Parker, S. (2013). Widening participation in Australian higher education. Report to the Higher Education Funding Council for England (HEFCE) and the Office of Fair Access (OFFA), England. Leicester/Lancashire: CFE (Research and Consulting) Ltd./Edge Hill University.

Houston, D. (2008). Systemic intervention in a university department: Reflections on arrested action research. Systemic Practice and Action Research, 21(2), 133-152.

Israel, B. A., Schulz, A. J., Parker, E. A., \& Becker, A. B. (2001). Community-based participatory research: Policy recommendations for promoting a partnership approach in health research. Education for Health, 14(2), 182-197.

Jackson, C. (2003). Transitions into higher education: Gendered implications for academic selfconcept. Oxford Review of Education, 29(3), 331-346. 
Kinnane, S., Wilks, J., Wilson, K., Hughes, T., \& Thomas, S. (2014). 'Can't be what you can't see': The transition of aboriginal and Torres Strait Islander students into higher education: Final report 2014. Sydney: Office for Learning and Teaching.

Liddle, C. (2016). First peoples: Aboriginal and Torres Strait Islander participation in higher education. In A. Harvey, C. Burnheim, \& M. Brett (Eds.), Student equity in Australian higher education: Twenty-five years of a fair chance for all. Singapore: Springer.

Martin, K. (2016). Handbook: The role of aboriginal knowledge in higher education in the 21st century. Canberra: Office of Learning and Teaching.

Nakata, M., Nakata, V., \& Chin, M. (2008). Approaches to the academic preparation and support of Australian Indigenous students for tertiary studies. The Australian Journal of Indigenous Education, 37, 137-145.

Nakata, M. (2012). CDSI plenary: Widening participation, social inclusion, closing the gap. Journal of Academic Language and Learning, 6(2), I1-I8.

Naylor, R., Baik, C., \& James, R. (2013). Developing a critical interventions framework for advancing equity in Australian higher education. Melbourne: Centre for the Study of Higher Education, the University of Melbourne.

Parent, A. (2014). Bending the box: Learning from indigenous students transitioning from high school to University. Unpublished doctoral dissertation. University of British Columbia, Vancouver, Canada.

Universities Australia. (2011). National best practice framework for indigenous cultural competency in Australian Universities. Retrieved from http://www.universitiesaustralia.edu.au/ page/311/policy-advocacy/indigenous-issues/cultural-competency/

Wheelahan, L. (2009). What kind of access does VET provide to higher education for low SES students? Not a lot. Student equity in higher education: What we know. What we need to know. University of South Australia: National Centre for Student Equity in Higher Education. Retrieved from http://www.unisa.edu.au/hawkeinstitute/events/default.asp

Open Access This chapter is licensed under the terms of the Creative Commons Attribution 4.0 International License (http://creativecommons.org/licenses/by/4.0/), which permits use, sharing, adaptation, distribution and reproduction in any medium or format, as long as you give appropriate credit to the original author(s) and the source, provide a link to the Creative Commons license and indicate if changes were made.

The images or other third party material in this chapter are included in the chapter's Creative Commons license, unless indicated otherwise in a credit line to the material. If material is not included in the chapter's Creative Commons license and your intended use is not permitted by statutory regulation or exceeds the permitted use, you will need to obtain permission directly from the copyright holder. 